\title{
Irritating, shocking, and intolerable TV programs: Norms, values, and concerns of viewers in The Netherlands
}

\author{
ARD HEUVELMAN, ALLERD PEETERS and JAN VAN DIJK
}

\section{Abstract}

This study investigates the negative reactions of Dutch viewers to the content of television programs. The results show that a vast majority is sometimes irritated by TV programs, that a somewhat smaller majority is sometimes shocked by the programs, and that one fifth of the viewing population consider certain programs to be intolerable. The most frequently mentioned genres are games, shows, and related entertainment programs, while reality $T V$ (scoring high on all negative reactions), news and current affairs (often shocking), and sex (often intolerable) are primarily evaluated as irritating. It appears that violent and frightening material creates by far the largest category of negative responses. Intimidating behavior worries the viewers most, immediately followed by the violation of privacy. This article also discusses the consequences of these results for broadcasting policy in the Netherlands.

Keywords: broadcasting regulations, television content, norms, values

\section{Introduction}

Since the introduction of television, matters of violence, sex, taste, and decency have been high on the agenda of debates on what is permitted in the content of television programs (Blumler, 1992).

With the rise of new genres such as reality TV and emotional TV in the past decade, matters of privacy were added to this list. Discussions about what is tolerable or not on television are held mainly in the inner circle of policy-makers and among journalists and media professionals. In this study, we turned to the forgotten participants in the debates and consulted the viewers; what are they worried about, what irritates them, what do they find shocking, and what programs should not be transmitted at all? 
Curiously enough these kinds of questions are hardly if ever asked in audience research. Both public and commercial broadcasters will stress the importance of probing the public about their programs, but in recent years audience research concentrates on ever more subtle and reliable audience ratings and programs' market shares. The results of such research do not supply sufficient information on what motivates viewers to watch certain programs, nor how they value these programs. Simply relying on rating figures as an indication of success or failure of programs does not offer enough support for planning and producing programs, unless the only goal is to provide advertisers with insight in the audience market (Hagen, 1999).

For commercial broadcasters it is fairly common to consider the audience as mere 'consumers', but such a view does not apply to public service broadcasting. Public broadcasters in many countries often maintain a normative relationship with their audiences, i. e., "they provide audiences with what they 'need', what is good for them" (Hagen, 1999: 137). In The Netherlands the public broadcasting organizations want to transmit programs, that "meet criteria of quality, that treat viewers honestly and respectfully" (NOS, 2000: 11), and wants to account for that in public. Unfortunately, it is unclear what these criteria and public accountability imply in practice.

In the recent past several authors have tried to establish criteria for quality assessment of television and public service broadcasting (e.g., Ishikawa, 1996). In drawing up such criteria most attention has been given to professional standards for program production, and far less to policy matters and the public interest. The question of the applicability of these criteria is hardly ever asked and usually remains unresolved, and is often seen as unproblematic (Raboy, 1996).

According to Rowland and Tracey (1990), the concept of public service broadcasting has become a controversial one in the major industrialized democracies in the past decades. We have seen a struggle over two opposed models. One model suggests that to sustain the well-being of society, we need specially qualified and appointed institutions to make strategic decisions and interventions to guarantee a certain quality of broadcasting in terms of range, depth, quality, and independence of program output. The other model contends that regulation through public policy is neither justified nor necessary. Media, this second model suggests, operate in a free marketplace where consumer sovereignty is what matters most.

In the United States the latter model prevails (Rowland and Tracey, 1990), whereas in, for instance, Canada specific rules and regulations apply. Divergent models operate in Europe. Some countries have explicit broadcasting regulations, while other countries, for instance The Nether- 
lands, do not have such regulations. In some countries in North Western Europe explicit rules and regulations stipulate what is permitted and what is not regarding the content of television programs, be it through legislation or not (Bardoel and d'Haenens, 2003). This means that an enforcement of 'standards' in program content exists, e.g., in Belgium and Great Britain, with explicit regulation regarding matters of sex, violence, and decency in the content of television.

The Netherlands have a rather unrestrictive regime of self-regulation, which is not based on explicit norms and rules. The Dutch 1987 Media Law contains no clause requiring respect for public order and good morals, and there is no specific legal control over matters of sex, violence, taste, decency, etc. in the content of television. This means that the enforcement of standards is largely left in the hands of the broadcasting associations, most of which have an explicit normative identity, e.g., Catholic or Protestant (McQuail, 1992a). Since 2001, Dutch public television does have a 'warning system', aimed at parents of children, indicating through symbols whether a program contains discriminating, sexual, violent, or frightening material, or contains use of drugs or alcohol, and/or offensive language. Additionally, there is the Dutch Media Authority, called 'Commissariaat voor de Media', but this institution is mainly concerned with the supervision of program regulations, surreptitious advertising, and sponsoring. This supervision or monitoring of programs is always post facto, so the programs are free of censorship. The monitoring is mainly used to assess whether public service and private broadcasters comply with the regulations for advertising and sponsorship. The Commissariaat also supervises whether broadcasters comply with their so-called program regulations, i.e., the percentage of time that is to be devoted to European productions, programs of independent producers (an EU-Directive), and - for public service broadcasters only - the percentage of time that has to be devoted to information, culture, and education in TV programs. When other complaints about program content are raised by viewers, the Commissariaat advises them to contact the broadcasting association involved. As soon as specific complaints are raised, the viewer can turn to organizations that take care of the protection of special interests, such as Anti-Discrimination Bureaus or the 'Bond tegen het vloeken', the league against blasphemy and swearing.

According to McQuail (1997) we have experienced an increasing significance of media, especially television, and a declining capacity to control them on behalf of the general good. The development of broadcasting requires that broadcasting organizations are held accountable for meeting a number of obligations, including deploying criteria that represent the values and needs of 'society' (McQuail, 1992b). In The Nether- 
lands, the question of morals and decency was not high on the agenda until recently (McQuail, 1992a). Only in the last couple of years a more substantial public debate has been taking place, mainly as a consequence of new reality formats such as Big Brother. However, just because moral decency has become an issue in the public debate of media professionals and policy-makers does not necessarily mean that the issue is a matter of popular concern. So, we have to ask ourselves whether the Dutch viewers are really concerned or have complaints about what is offered to them by their three public and eight commercial stations. Are they concerned, and do they have complaints about certain programs, and if so, what are the main issues? Are their concerns and complaints related to their own norms and values? Moreover, do they think that particular programs are a threat to the values and needs of society at large?

Audience research on complaints and other negative reactions is scarce and incidental. Research on complaints appears to be limited to irritation provoked by advertising on TV (e.g., Fennis and Bakker, 2001; Smit, 1999). Moreover, research on television programs hardly ever includes viewers' norms and values as variables. Nevertheless, as Alasuutari (1992) already argued, when one listens to people talking about television programs, it is striking how profoundly moral their opinion is. Evaluations of programs often contain normative judgments and value judgments, especially on a number of specific genres. However, research has largely taken the moral character of television discourse for granted (Alasuutari, 1992). Disliking TV content may even perform an important function in society; previous research indicates that people like to complain and exchange their negative feelings with others, because it provides them with a social bond (e. g., Ang, 1985). As such, negative feelings about popular mass media are socially valuable.

The debate about the quality of television programs is as old as the medium itself. However, serious empirical study of the quality of television programs did not begin until the early 1990s (e. g., Wober, 1990). It is true that measurement of viewers' appreciation of programs has been going on for several decades (Gunter and Wober, 1992). The extent to which viewers say they like or appreciate programs, however, is a poor indicator of program quality. As Wober (1990) has shown, viewers may express appreciation of programs which they themselves say are of low quality. An objective assessment of the quality of television programs is not possible, because there is no consensus on the standards that programs should meet. But if there were such a consensus, it would be impossible to objectively determine the quality of television programs, because there are no objective assessment instruments available. The researcher who wishes to establish standards of quality for television programs, or to determine the extent to which a specific program meets 
these standards, has no choice but to rely on evaluations provided by human judges (Nikken, 1999).

In this research project we made an explicit choice to construct an inventory of negative reactions to the content of television programs, and exclude the positive ones so common to audience research. It concerns negative reactions involving the personal ideologies of the viewer and the manifestations of these ideologies in individual value systems, religion, political orientation, and norms about human conduct (De St. Aubin, 1996). Such negative reactions will often be (very) emotional because they are reactions to people's conduct, situations, or to events presented on the screen that might be in conflict with how people think they should behave or how the world should be. That is why emotions such as anger, fear, disgust, distress, or shame are at the core of these negative reactions. More specifically, negative reactions will be considered affective reactions, characterized by negative valence and by moderate or strong arousal (Musch and Klauer, 2003). Moreover, viewers' norms and values will be at stake, be it viewers' norms regarding what is or is not permitted on television, or norms and values on what constitutes 'good quality' of TV programs. However, we do not want to guide respondents in a certain direction, in the sense that specific negative aspects are mentioned in questions like 'ugly', 'banal', 'violent', or 'disgusting'. That is why we chose to use three broad categories of negative reactions: 'irritating', 'shocking', and 'intolerable', all of which have to do with negative valence, a certain amount of arousal, and viewers' norms and values. So we differentiated between the following three types of negative reactions:

1 Reactions concerning program contents that conflict with viewers' values and norms of what should be permitted on television and which lead to the judgment 'intolerable';

2 Reactions concerning program contents that conflict with viewers' values and, amplified by negative emotions, lead to 'irritation';

3 Reactions concerning program contents that conflict with viewers' values and, amplified by strong negative emotions, lead to a state of 'being shocked'.

This division of negative reactions into three broad categories may not be an exhaustive list of all possible negative reactions to TV content, but it is sufficient for our exploratory purposes. Because of possibly strong negative emotions associated with 'shocking' content, we deemed it sensible to save that aspect for last when asking for viewers' negative reactions. For a similar reason we also thought it was wise to start off with the negative reaction of the least emotional impact ('irritating'), followed 
by the more severe judgment of 'intolerable'. Following De St. Aubin's (1996) theory on people's personal ideologies we also looked into viewers' individual and social value systems, their religion, their political orientation, and their norms about human conduct, in order to see if, and in what way, these variables are related to negative reactions. Furthermore, we investigated whether other personal characteristics of viewers - sex, age, educational level, and TV viewing time - have a direct effect on negative reactions.

Finally, we asked if viewers were concerned about television content in The Netherlands. We presented 17 matters of possible concern from the traditional debates about TV content, such as matters of violence, sex, taste, and decency, and some 'new' concerns, such as violation of privacy. These concerns may be related to viewers' negative reactions to current TV content, but not necessarily so because, as stated earlier in this introduction, these concerns stem from the inner circle of policymakers and media professionals.

The nature of our research is exploratory as current theory on the subject is rather poor and current research does not provide empirical evidence. We will answer the following descriptive research questions:

- What is the distribution of negative reactions of viewers (irritation, being shocked, and finding programs intolerable) in terms of program genres?

- What do viewers complain about when they indicate they find a program irritating, shocking, or intolerable?

- What are the relationships between the three types of negative reactions and viewer characteristics, such as sex, age, educational level, religion, political preference, values, norms, and time spent on watching television?

- What are the general concerns of viewers watching programs on Dutch TV?

\section{Method}

A telephone survey was conducted among Dutch television viewers in July 2002. KPN, the Dutch national telephone company, provided us with an a-select sample from their database. To select the respondent the 'next birthday' method was used, where interviewers asked to speak with the member of the household 15 years or older who has the next birthday. The non-response rate was $44 \%$ (refusals, three times no answer, selected person not at home and not possible to make an appointment, refusal in second instance, etc., wrong numbers excluded). The telephone 
conversations were held by trained interviewers with the aid of a CATIsystem. The interviews were conducted during afternoon and evening hours. An interview took 30 minutes on average.

\section{Respondents}

A total of 495 respondents participated, but five of them indicated that they never watched television and were, consequently, excluded from our main analyses. After checking the characteristics sex, age, and educational level, it appeared that the composition of this sample (non-viewers included) slightly deviated from the Dutch population. Men, younger respondents (15-29 years of age), and lower educated people were slightly underrepresented. Consequently we weighted the sample to match national parameters for sex, age, and education, by which means the results can be considered as representative for the Dutch population (15 years and older).

\section{Questionnaire}

The questions about negative reactions contained the following openended structure: "Do you get so irritated watching a TV program, that you no longer want to watch it ...", if yes, followed by "Does this occur often, sometimes or not often" and "Could you give me one or more examples?", with a maximum of three examples. The subsequent questions for intolerable and shocking programs were comparable. This procedure allowed the respondents to mention programs on the one hand and complaints about program content on the other, and gave them the opportunity to not only mention specific programs, but also program genres, specific parts of programs, specific presenters, etc.

Another category of questions were aimed at viewers' concerns, norms and values, and several other viewer characteristics. The questions about viewers' concerns were structured as follows. We presented 17 reasons why people might be worried about the contents of TV programs, such as the display of violence on the screen, sex, racism, discrimination, the use of strong language, etc., and asked if the respondent was 'very', 'a bit', or 'not at all' concerned about each of these reasons.

Furthermore, we presented 20 value statements (Rokeach, 1973), consisting of social values (e.g., equality, security, respect), and personal values (e.g., a comfortable life, a quiet life, an active life), and asked respondents to rate each of these values on a scale from 1 to 10 .

The normative statements concerned the preservation of norms and values ("Our society is declining, because too little attention is paid to values and norms" and "In The Netherlands too much remains unpun- 
ished and too much is tolerated") and some specific norms on privacy ("Some matters are too intimate or personal to discuss even with your best friends" and "In my daily life many circumstances give me the feeling that my privacy is being violated") and sexual morality ("It is important to save sex for marriage" and "Sex is only acceptable where there is real love"). Respondents could 'fully agree', 'partly agree', or 'not agree' with each of these statements. For practical reasons we only made a selection of normative statements.

The questionnaire started with two questions about TV viewing time. Viewing time can be computed as the product of the respondent's estimation of the mean number of days a week viewing TV and the estimation of mean viewing time during these days. Next the respondents judged the content of public and commercial TV stations in the Netherlands (in a randomized order) by means of a mark varying from 1 (very bad) to 10 (excellent).

In the final section the questionnaire the respondents' sex, age, educational level, religion (importance of religion and religious community), and political preference were determined. Several other questions were also posed in an earlier section of the interview, but they are beyond the scope of the present article.

\section{Results}

To get an indication of the evaluation of the quality of public and commercial Dutch television stations the respondents were requested to judge the content by means of a score varying from 1 (very bad) to 10 (excellent) in the first section of the questionnaire. It appeared that the quality of TV content, both public and commercial stations, is considered rather low. The quality of public stations is unsatisfactory $(1-5)$ according to $14 \%$ and just satisfactory (6) according to $27 \%$ of the viewers. The quality of commercial stations is unsatisfactory for $21 \%$ and just satisfactory for $26 \%$ of the viewers.

The frequencies of all negative reactions are presented in Table 1 . The results show that $80 \%$ of the Dutch viewers are sometimes irritated by TV programs, $23 \%$ of these viewers even quite often. Almost $50 \%$ of them find programs shocking every now and then, and $20 \%$ consider certain programs intolerable.

Our first research question is: "What is the distribution of negative reactions of viewers (irritating, being shocked, and finding programs intolerable) in terms of program genres?" Table 2 presents the percentages of negative reactions for a number of genres, the ones mentioned most often by the respondents. This list by no means represents an 'official' classification of genres, but only genres perceived as such by viewers. 
Table 1. Frequencies of negative reactions to television programs by Dutch viewers (percentages, $N=490$ ).

\begin{tabular}{lllll}
\hline & $\begin{array}{l}\text { negative total } \\
(1,2 \text { or } 3)\end{array}$ & $\begin{array}{l}\text { irritating } \\
(1)\end{array}$ & $\begin{array}{l}\text { shocking } \\
(2)\end{array}$ & $\begin{array}{l}\text { intolerable } \\
(3)\end{array}$ \\
\hline Sometimes/yes & 91.1 & 80.2 & 65.1 & 21.1 \\
$\quad$ - often & & 23.1 & 3.7 & \\
- now and then & & 47.0 & 43.6 & \\
$\quad$ - occasionally & & 10.1 & 17.7 & \\
never/no or don't know & 8.9 & 19.8 & 34.9 & 79.9 \\
\hline
\end{tabular}

Table 2. Television genres with (kinds of) negative reactions by Dutch viewers (percentages of answers).

\begin{tabular}{llccc}
\hline & $\begin{array}{l}\text { negative } \\
(\mathrm{N}=800)\end{array}$ & $\begin{array}{l}\text { irritating } \\
(\mathrm{N}=464)\end{array}$ & $\begin{array}{l}\text { shocking } \\
(\mathrm{N}=236)\end{array}$ & $\begin{array}{l}\text { intolerable } \\
(\mathrm{N}=100)\end{array}$ \\
\hline 1. game, show, related & 17 & 26 & 3 & 7 \\
$\quad$ entertainment & 15 & 16 & 14 & 10 \\
2. reality & 13 & 5 & 32 & 4 \\
3. news and actualities & 11 & 16 & 3 & 7 \\
4. talk shows & 8 & 4 & 7 & 30 \\
5. sex & 7 & 11 & 1 & 3 \\
6. soap & 6 & 2 & 14 & 6 \\
7. extreme & 4 & 4 & 4 & 7 \\
8. action, crime, horror & 3 & 2 & 6 & 1 \\
9. medical & 11 & 10 & 10 & 17 \\
other genres * & 6 & 5 & 6 & 8 \\
genre not specified & & & & \\
\hline
\end{tabular}

* other genres mentioned: comedy, other drama, documentaries, crime reports, other informative, youth programs, music, advertising, religious programs, satire, sport.

Games, quizzes, and related entertainment receive most of the negative reactions, with irritation scoring the highest. Reality programs such as Big Brother also provoke quite a few negative reactions. A remarkable finding in regard to this genre is that it elicits irritation, a shocked reaction, and the judgment 'intolerable' in an almost evenly fashion. News and current affairs are considered the most shocking genre, and sex is the most intolerable one according to the viewers. The other identified genres receive relatively few negative reactions, contrary to what might have been expected in the case of advertising, be it commercials or clandestine advertising in the form of product placement (which is outlawed in The Netherlands).

"What do viewers complain about when they indicate they find a program irritating, shocking, or intolerable?", was our second research question. The results of our analyses on this subject are presented in Table 3. 
Table 3. Complaints raised with negative reactions to television programs by Dutch viewers (percentages of answers).

\begin{tabular}{lcccc}
\hline & $\begin{array}{c}\text { negative } \\
(\mathrm{N}=800)\end{array}$ & $\begin{array}{l}\text { irritating } \\
(\mathrm{N}=464)\end{array}$ & $\begin{array}{l}\text { shocking } \\
(\mathrm{N}=236)\end{array}$ & $\begin{array}{l}\text { intolerable } \\
(\mathrm{N}=100)\end{array}$ \\
\hline 1. violent/frightening & 18 & 5 & 42 & 18 \\
2. trivial & 7 & 11 & 2 & 3 \\
3. no respect & 7 & 9 & 3 & 4 \\
4. sex/nudity & 7 & 3 & 5 & 25 \\
5. strong language & 5 & 4 & 4 & 8 \\
6. unrealistic & 4 & 6 & - & 2 \\
7. repetition & 4 & 6 & - & 1 \\
8. presenter & 4 & 6 & - & 2 \\
9. uninteresting & 3 & 5 & - & 2 \\
10. sensation eager & 3 & 4 & 3 & 1 \\
11. immoral & 3 & 1 & 6 & 6 \\
12. privacy & 3 & 3 & 2 & 5 \\
other complaints * & 11 & 28 & 15 & 7 \\
complaint not specified & 21 & 9 & 18 & 14 \\
\hline
\end{tabular}

* other complaints mentioned: suffering of humans/animals, distasteful, bad quality, dull, not objective, boring, programming, discrimination, occult/antireligious.

As the results show, most complaints are related to violent and frightening content. Not all material that frightens people is violent (e. g., medical programs) and vice versa (unrealistic, yet violent, cartoons are not considered frightening), but in practice it is often impossible to distinguish answers containing complaints about violence from answers with complaints about frightening content (for example, "Realistic violence in news and feature programs because violence shown is graphic and explicit", "9/11: too many images were shocking and confronting", "Extreme violence in films", "Shouting and screaming in the Jerry Springer show", "Murders in TV programs"). Complaints related to violent and frightening content make up $42 \%$ of the negative reaction 'being shocked' and $18 \%$ of the negative reaction 'intolerable'. When we look at 'irritanting' reactions only, we can see that the reasons for being irritated by program content are very diverse. Moreover, complaints uttered for being irritated also seem to be related to the professional or production quality of programs ('trivial', 'unrealistic', 'repetition', 'presenter', and 'uninteresting') as well as to reasons related to norms and values ('no respect', 'sex', 'strong language', 'immoral', 'privacy'). Sex was mentioned most as a reason to consider a program intolerable.

The open-ended questions about negative reactions gave respondents the opportunity to not only mention programs belonging to specific genres, but also to complain about these programs. All answers were qualitatively categorized by program genre (research question 1) and 
type of complaint (research question 2). Sometimes the program genre or the complaint was not specified. Complaints about violent/frightening content in which no program or program genre was mentioned account for one quarter of negative reactions; strong language and sex/nudity were also mentioned more than once without specification of the program genre. Negative reactions without specification of the complaint frequently concerned games, shows, and other entertainment programs $(22 \%)$; other program genres often mentioned without an explicit complaint were reality programs and talk shows.

Our third research question was: "What are the relationships between the three types of negative reactions and viewer characteristics?" In Table 4 correlations between the frequency of negative reactions and the viewer characteristics are presented: sex, age, educational level, importance of religion, religion, political preference, importance of social values (10 items, Cronbach's alpha $=.82)$, importance of personal values (6 items, Cronbach's alpha $=.67)$, preservation of norms and values ( 2 items, $\mathrm{r}=.36$ ), need for privacy ( 2 items, $\mathrm{r}=.19$ ), traditional sexual morality ( 2 items, $r=.26$ ), TV viewing time, and general evaluation of public and commercial stations.

Although negative reactions will most probably be related to many other variables, the correlation matrix does show a number of interesting data. Concerning demographics, it appears that being shocked by programs correlates significantly with the viewer's sex (women are often more shocked than men, $\mathrm{r}=.18, \mathrm{p}<.001)$, considering a program intolerable with the viewer's age (older viewers are more likely to find programs intolerable that younger ones, $\mathrm{r}=.10, \mathrm{p}<.05)$, and being irritated with the viewer's level of education (higher educated viewers are more inclined to being irritated than lower educated viewers, $\mathrm{r}=$ $.12, \mathrm{p}<.05)$. Being shocked by programs correlates significantly with a viewer's religion: Viewers who attach more importance to religion are more easily shocked by television $(r=.15, \mathrm{p}<.001)$, especially Roman Catholics and Protestants. Political preference does, however, not correlate significantly to any of the negative reactions. When it concerns viewers' norms and values, it appears that viewers who emphasize the preservation of norms and values score higher on all three negative reactions, i. e., irritating $(\mathrm{r}=.14, \mathrm{p}<.01)$, shocking $(\mathrm{r}=.10, \mathrm{p}<.05)$, and intolerable $(\mathrm{r}=.13, \mathrm{p}<.01)$. When we look at the influence of personal and social values on negative reactions, it turns out that only social values are important. In this respect, viewers who emphasize the importance of social values are more inclined to regard programs as intolerable $(\mathrm{r}=$ $.11, \mathrm{p}<.05)$. Respondents with a greater need for privacy are more easily shocked by programs $(\mathrm{r}=.12, \mathrm{p}<.01)$. But, traditional sexual morality does not correlate significantly with the frequency of negative 
Table 4. Correlations of negative reactions to television programs of Dutch viewers with viewer characteristics.

\begin{tabular}{|c|c|c|c|c|}
\hline & negative & irritating & shocking & intolerable \\
\hline $\operatorname{sex}(m=1, f=2)$ & $.10 *$ & .00 & $.18 * * *$ & .04 \\
\hline age & $.11(*)$ & .03 & .07 & $.10(*)$ \\
\hline educational level & .05 & $.12 *$ & .01 & -.02 \\
\hline importance of religion & .05 & -.04 & $.15(* * *)$ & .01 \\
\hline - Roman Catholic & .00 & -.03 & $.10(*)$ & -.05 \\
\hline - Protestant & .02 & -.05 & $.11(*)$ & -.01 \\
\hline - other & .09 & .09 & .00 & .07 \\
\hline- non-religious & -.04 & .04 & $-.17(* * *)$ & .03 \\
\hline \multicolumn{5}{|l|}{ political preference } \\
\hline - CDA, LPF, LN, CU, SGP & .06 & -.02 & .06 & .07 \\
\hline - PvdA, vvD, D66 & -.09 & -.03 & -.06 & -.08 \\
\hline - GroenLinks, SP & .03 & .07 & .00 & .00 \\
\hline- none & .03 & .03 & .01 & .02 \\
\hline importance social values & .06 & -.01 & .02 & $.11 *$ \\
\hline importance personal values & -.01 & -.04 & .03 & $-.01 \#$ \\
\hline preservation norms and values & $.19 * * *$ & $.14 * *$ & $.10 *$ & $.13(* *)$ \\
\hline need for privacy & $.10(*)$ & .03 & $.12 * *$ & .04 \\
\hline traditional sexual morality & .05 & .00 & .07 & .04 \\
\hline TV viewing time & -.02 & -.09 & .02 & .03 \\
\hline $\begin{array}{l}\text { general evaluation of public } \\
\text { stations }\end{array}$ & -.02 & -.08 & .01 & .02 \\
\hline $\begin{array}{l}\text { general evaluation of } \\
\text { commercial stations }\end{array}$ & $-.21 * * *$ & $-.17 * * *$ & -.03 & $-.19 * * *$ \\
\hline
\end{tabular}

*** $\mathrm{p}<.001, * * \mathrm{p}<.01, * \mathrm{p}<.05$. Between brackets: not significant in multiple regression analysis.

\# Significant in multiple regression analysis only $(\beta=-.13, \mathrm{p}<.05)$.

reactions. It is remarkable that viewers' time spent on watching TV does not correlate with the negative reactions either. Finally, people who appreciate the program supply of commercial TV stations are less often irritated by programs $(\mathrm{r}=-.17, \mathrm{p}<.001)$ and less inclined to consider programs as intolerable $(\mathrm{r}=-.19, \mathrm{p}<.001)$.

It should be noted that the correlations found are rather low and even lower at a multivariate level (9 of the 19 significant relations disappear in multiple regression analysis and only one showed up, $\mathrm{R}^{2}$ varies from .08 to .11 and adjusted $\mathrm{R}^{2}$ from .04 to .07 ). There can be several explanations for these low correlations. First of all, some of the independent variables may not have been adequately measured, such as the value scales based on Rokeach's (1973) value theory (it may be that either the scales were hard to translate into Dutch or that these values are culturally determined). It is also possible that we missed important predictors, such as viewers' sensitivity and/or other aspects of viewing behavior than viewing time. Finally, the fact that the dependent variables were mea- 
sured partly by means of open-ended questions could also have been of influence (it is entirely possible that viewers who may have negative feelings about certain programs are unable to produce an example when asked for it in an open-ended question).

We will now deal with our last research question: "What are the general concerns of viewers watching programs on Dutch TV?". Respondents were presented with reasons why people might be worried about the contents of TV programs, such as the display of violence on the screen, sex, racism, discrimination, the use of strong language, etc., and asked if the respondent was 'very', 'a bit', or 'not at all' concerned about each of these reasons. Answers were then transformed into a ten-point scale, purely for presentation goals, and a principal component factor analysis with Varimax rotation was run on these data extracting five factors with Eigenvalues greater than 1.0. Even though the reliability of the two more complex scales with the largest number of items ('offensive behavior' and 'violence and fear') was satisfactory (Cronbach's alpha was .85 and .75 , respectively), these scales correlated strongly $(\mathrm{r}=.63, \mathrm{p}<.001)$. Viewers' concerns can be grouped together into five factors, which we have called 'intimidating behavior', 'violation of privacy', 'offensive behavior', 'violence and fear', and 'deception'. Of the five types of concerns, 'violence and fear' had the strongest correlation with negative reactions to television content $(\mathrm{r}=.30, \mathrm{p}<.001)$, especially being shocked $(\mathrm{r}=.34, \mathrm{p}<.001)$. In Table 5 the mean scores for these concerns are presented. As it turns out, 'intimidating behavior' on the screen is what Dutch viewers worry about most (with an average score of 6.2),

Table 5. Concerns about television content among Dutch viewers after factor analysis $(0=$ not worried, $10=$ extremely worried $)$.

\begin{tabular}{llll}
\hline Factor & score $(0-10)$ & Factor & score $(0-10)$ \\
\hline Intimidating behavior & $\mathbf{6 . 2}$ & Violence and fear & $\mathbf{4 . 2}$ \\
racism/discrimination & 7.6 & violence in news & 3.9 \\
against women & 5.7 & violence in movies & 5.6 \\
& & frightening & 3.3 \\
Violation of privacy & $\mathbf{5 . 6}$ & unhealthy behavior & 5.7 \\
exhibitionism & 5.5 & hard interviewing & 2.7 \\
violation & 5.7 & Deception & $\mathbf{3 . 9}$ \\
& & not objective & 5.4 \\
Offensive behavior & $\mathbf{4 . 9}$ & clandestine advertising & 3.0 \\
nudity & 3.0 & gossip & 3.3 \\
sex & 4.0 & & \\
strong language & 6.3 & & \\
blasphemy & 5.6 & & \\
cursing & 5.8 & & \\
\hline
\end{tabular}


followed by 'violation of privacy' (5.6), 'offensive behavior' (4.9), 'violence and fear' (4.2), and 'deception' (3.9). There are, however, some remarkable differences within the factors found in the analysis. Within the factor 'offensive behavior', Dutch viewers especially worry about strong language, cursing, and blasphemy, and far less about sex and nudity. Within the factor 'violence and fear', Dutch viewers are most worried about the depiction of unhealthy behavior (such as using drugs or alcohol), and violence in movies, and far less about violence in news, frightening pictures, and tough interviews.

\section{Conclusions and discussion}

It appears from the results of this research project, that a vast majority of television viewers in The Netherlands is sometimes irritated by TV programs, that a somewhat smaller majority is sometimes shocked by the programs, and that one fifth of the viewing population consider certain programs to be intolerable.

This major conclusion should be put into a broader perspective, because the answers were found among a sample that was probed to respond negatively, instead of asked to present an open view on the general quality of TV. Additionally, we also asked for a general evaluation of public and commercial TV stations before asking about specific negative reactions to programs. It appeared that the quality of TV content, regarding both public and commercial stations, is considered to be rather poor. Negative reactions correlated significantly with the general evaluation of commercial stations' quality. This was only applicable to reactions of irritation and some programs being intolerable, not to shocked reactions.

The genres that were mentioned most frequently in negative reactions are game shows and related entertainment programs. The programs that were primarily deemed irritating were reality TV (scoring high on all negative reactions), whereas news and current affairs were often perceived as shocking, and sex was often seen as intolerable. A remarkable finding is that (clandestine) advertising, although monitored closely by the Dutch Media Authority, is not much of an issue for the Dutch viewers, not even as a source of irritation. It should be pointed out here, that we did not investigate viewers' irritation caused by commercials on TV, which may not be considered as 'programs' by viewers. Clandestine advertising, however, receives very few negative reactions, and is not a matter of great concern. We would like to point out here that the number of negative reactions might even be an under-representation, because they were investigated by means of open-ended questions. The larger 
number of negative responses to pre-coded questions, for instance, the questions about viewers' concerns, gives rise to this assumption.

When it comes to the complaints mentioned when viewers react negatively to current TV content in The Netherlands, it appears that violent and frightening material creates by far the largest category of negative responses, considered mainly as shocking and intolerable. As to the other complaints, sexually explicit material is primarily considered intolerable, but not so much shocking and far less irritating. Furthermore, when we look at the category of negative reactions called irritating, the diversity of answers stands out. Complaints concerning irritation are not only related to norm- and value-laden reasons, but also to the professional and production quality of programs. The main current issues of complaint concerning Dutch TV content are 1) violence and fear in programs, 2) to a lesser degree sex, and 3) professional and production quality. Advertising is not an important issue.

When we look at the viewers' concerns about TV content, another pattern of results emerges. That is to say, intimidating behavior (racism/ discrimination, unfriendly behavior towards women) worries the viewers most. This is immediately followed by the violation of privacy. In the context of concerns, violence and fear play a less significant role. There may be several reasons for the occurrence of these results. First of all, concerns may be projected on the potential future degeneration of content, and viewers may see the signs for their worries in already existing programs. Secondly, the questions about concerns were not openended, and possibly gave rise to socially desirable answers, contrary to the negative reactions which had to be produced from 'top of head' experience. When we compare viewers' complaints and concerns it appears that complaints about shocking and intolerable content - such as 'violent', 'frightening', 'no respect', 'sex', 'nudity', 'strong language', 'immoral', and 'privacy' - become manifest in viewers' concerns. The negative reactions caused by irritation mostly had to do with the quality of the programs; respondents would refer to the programs' content as 'trivial', 'unrealistic', 'repetition', and 'uninteresting'. Therefore, in future research it seems that concerns about program quality have to be taken into account. In this research project we asked for negative reactions by means of open-ended questions and for concerns by means of pre-coded questions. As Gunter (1997) remarked, the program attributes which are presented to respondents should be based on pilot studies that tap the standards used spontaneously by the group of judges concerned. Otherwise it remains unclear whether the quality standards found through factor analysis indeed hold for the group of judges under investigation and are actually used by them. 
However, we do not have a clear enough picture of what is measured precisely by asking people if they consider content as irritating, shocking, and intolerable. Our results suggest that these three concepts do really measure different reactions. We are able to observe this through the different sorts of complaints viewers raise when they are asked why something on TV is considered irritating, shocking, or intolerable. Moreover, the correlations of these negative reactions with viewer characteristics are different for each of the three types of reactions. But we need to know more about the relationship between these three reactions and viewers' (other) norms, values, and emotions. One of the many problems seems to be the order in which these negative reactions were asked for. The distribution of responses across the three types of negative feelings may be a result of an artifact, since respondents will have given many examples regarding the first question and could only think of a couple more examples regarding the last question. This artifact cannot be countered by presenting the three types of questions in a random order for each respondent because some orders are problematic as indicated in the introductory paragraph. The best way to deal with the problem seems to be to ask the questions regarding the three different reactions to three different samples in future research.

Finally, we need to make some remarks about the potential consequences of our results for broadcasting policy in The Netherlands. Are the results of this representative sample of the Dutch viewers sufficiently relevant to suggest policy changes concerning the legitimacy, the accountability, and the regulations of broadcasting organizations in The Netherlands? We think they are, or at least that there is enough evidence to suggest that the current system in the Netherlands is inadequate. The existing regulations do not provide the viewers with sufficient means or ways to raise complaints about the content of programs. In fact, the means for public accountability of broadcasting organizations are lacking.

As discussed before, there is a 'warning system' for parents, indicating whether a program contains discriminating, sexually explicit, violent, or frightening material, or that it portrays the use of drugs and alcohol, or that it uses offensive language. However, the optional extension of this instrument with an application for adults would not solve our problem. We do not think it is appropriate to anticipate all sorts of potentially negative reactions from the public with such an instrument. The warning system for parents is explicitly intended for possible harmfulness to children, and is not based on disputable norms, values, and opinions on what is acceptable (see also Valkenburg, Beentjes, Nikken, and Tan, 2002). We would not aim for an instrument of detecting potential controversial material in advance, but rather for the explicit clarification of the 
norms and values the broadcasting organizations themselves use when deciding about programs and programming. As already mentioned in the introduction, the current situation in The Netherlands has the character of self-regulation with implicit norms. Viewers' negative reactions do not play a part in audience research and, what is more, complaints tend to 'vanish' into thin air because they are scattered over all broadcasting organizations.

In our view, two things need to be done to change this situation. First of all, current audience research should not only ask viewers for their appreciation of the programs they watch, but also allow them to express potentially negative reactions. And secondly, we would like to recommend the installation of a particular public 'counter', perhaps a special website, for negative reactions and complaints from the audience. In this way a file of these reactions is composed for the use of broadcasters, policy-makers, consumer organizations, special interest groups, and for the general public. This will give the broadcasting organizations the opportunity to account for and explicate the norms and values in their programs and programming.

\section{References}

Alasuutari, P. (1992). "I'm ashamed to admit it but I have watched Dallas": The moral hierarchy of television programs. Media, Culture and Society, 14(4), 561-582.

Ang, I. (1985). Watching Dallas: Soap opera and the melodramatic imagination. New York: Methuen.

Bardoel, J. and d'Haenens. L. (2003). Media en maatschappelijke verantwoordelijkheid: Van theorie naar praktijk [Media and social responsibility: From theory to practice]. In Raad voor Maatschappelijke Ontwikkeling (Ed.), Medialogica; Over het krachtenveld tussen burgers, media en politiek; Advies 26 (pp. 99-151). The Hague: RMO / Sdu.

Blumler, J. G. (Ed.). (1992). Television and the public interest: Vulnerable values in West European broadcasting. London: Sage.

De St. Aubin, E. (1996). Personal ideology polarity: Its emotional foundation and its manifestation in individual value systems, religiosity, political orientation, and assumptions concerning human nature. Journal of Personality and Social Psychology, 71(1), 152-165.

Fennis, B. M. and Bakker. A.B. (2001). "Stay tuned - We will be back right after these messages": Need to evaluate moderates the transfer of irritation in advertising. Journal of Advertising, 30(3), 15-26.

Gunter, B. (1995). Understanding the appeal of TV game shows. Medienpsychologie, $7(2), 87-106$.

Gunter, B. (1997). Media appreciation and use. In P. Winterhoff-Spurk and T. van der Voort (Eds.), New horizons in media psychology (pp. 11-34). Opladen: Westdeutscher Verlag.

Gunter, B. and Wober, M. (1992). The reactive viewer: A review of research on audience reaction measurement. London: John Libbey.

Hagen, I. (1999). Slaves of the ratings tyranny? Media images of the audience. In P. Alasuutari (Ed.), Rethinking the media audience (pp. 130-150). London: Sage. 
Ishikawa, S. (Ed.). (1996). Quality assessment of television. Luton: John Libbey Media.

McQuail, D. (1992a). The Netherlands: Freedom and diversity under multichannel conditions. In J.G. Blumler (Ed.), Television and the public interest: Vulnerable values in West European broadcasting (pp. 96-111). London: Sage.

McQuail, D. (1992b). Media performance: Mass communication and the public interest. London: Sage.

McQuail, D. (1997). Accountability of media to society: Principles and means. European Journal of Communication, 12(4), 511-530.

Musch, J. and Klauer, K.C. (2003) The psychology of evaluation: An introduction. In J. Musch and K.C. Klauer (Eds.), The psychology of evaluation: Affective processes in cognition and emotion (pp. 1-5). Mahwah, NJ: Erlbaum.

Nikken P. (1999). Quality in children's television. Unpublished doctoral dissertation, University of Leiden, The Netherlands.

NOS (2000). Verschil maken: Concessiebeleidsplan landelijke publieke omroep 20002010 [Making a difference: Licensing policy plan national public service 20002010]. Hilversum: NOS.

Raboy, M. (1996). Towards a new ethical environment for public service broadcasting. In S. Ishikawa (Ed.), Quality assessment of television (pp. 265-286). Luton: John Libbey.

Rokeach, M. (1973). The nature of human values. New York: The Free Press.

Rowland, W. D. and Tracey, M. (1990). Worldwide challenges to public service broadcasting. Journal of Communication, 40(2), 8-27.

Smit, E. (1999). Mass media advertising: Information or wallpaper? Amsterdam: Het Spinhuis.

Valkenburg, P., Beentjes, H., Nikken, P., and Tan, E. (2002). Kijkwijzer: The Dutch rating system for audiovisual productions. Communications: The European Journal of Communication Research, 27(1), 79-102.

Wober, M. (1990). The assessment of TV quality: Some explorations of methods and their results. London: London Independent Broadcasting Authority. 